\title{
Mycobacterium florentinum sp. nov., isolated from humans
}

\begin{abstract}
Correspondence
Enrico Tortoli e.tortoli@libero.it
\end{abstract}

\author{
Enrico Tortoli, ${ }^{1}$ Laura Rindi, ${ }^{2}$ Khye S. Goh, ${ }^{3}$ Marja L. Katila, ${ }^{4}$ \\ Alessandro Mariottini, ${ }^{1,5}$ Romano Mattei, ${ }^{6}$ Gianna Mazzarelli, ${ }^{1,7}$ \\ Sini Suomalainen, ${ }^{8}$ Pirjo Torkko ${ }^{4,9}$ and Nalin Rastogi ${ }^{3}$ \\ ${ }^{1,5,7}$ Regional Reference Center for Mycobacteria, Microbiology and Virology Laboratory ${ }^{1}$, \\ Genetics and Cytogenetics Unit ${ }^{5}$ and Microbiological and Virological Serum-immunology \\ Laboratory ${ }^{7}$, Careggi Hospital, 50134 Florence, Italy \\ ${ }^{2}$ Department of Experimental Pathology, Medical Biotechnologies, Infectivology and \\ Epidemiology, University of Pisa, 56127 Pisa, Italy \\ ${ }^{3}$ Unité de la Tuberculose et des Mycobactéries, Institut \\ Pasteur de Guadeloupe, 97165 Pointe-à-Pitre, Guadeloupe, France \\ ${ }^{4}$ Department of Clinical Microbiology, Kuopio University Hospital, 70211 Kuopio, Finland \\ ${ }^{6}$ Clinical Laboratory, Campo di Marte Hospital, 55100 Lucca, Italy \\ ${ }^{8}$ Institute of Biotechnology, University of Helsinki, 00014 Helsinki, Finland \\ ${ }^{9}$ Laboratory of Environmental Microbiology, National Public Health Institute, 70211 Kuopio, \\ Finland
}

\begin{abstract}
Eight mycobacterial strains isolated during an 11 year period from the sputum of independent patients with various pulmonary disorders and, in one case, from a lymph node of a young girl, were found to present identical features. Phenotypic and genotypic characteristics revealed that the most closely related species to these test isolates were Mycobacterium triplex and Mycobacterium lentiflavum. However, the lipids of the cell wall of the test isolates differed from those of the latter species by TLC and presented unique profiles by both GC and HPLC.

Genotypic analysis showed that they had unique 16S rRNA gene and internal transcribed spacer (ITS) sequences, and could be differentiated from all other mycobacterial strains by PCR restriction analysis of $h s p 65$. The strains presented high resistance to antimycobacterial drugs. The name Mycobacterium florentinum sp. nov. is proposed for this taxon, with strain $\mathrm{FI}-93171^{\top}$ $\left(=\mathrm{DSM} 44852^{\top}=\right.$ CIP $\left.108409^{\top}\right)$ as the type strain.
\end{abstract}

In recent years many novel mycobacterial species have been discovered and detailed genetic characterization has helped define new taxonomic groupings (Tortoli, 2003). A group genetically related to Mycobacterium terrae has been recognized within the slowly growing mycobacteria, and a group of thermotolerant mycobacteria has been characterized within the rapid growers (Tortoli, 2003). However, the more striking new taxonomic entity is the one related to Mycobacterium simiae, which presents genetic features

Published online ahead of print on 9 December 2004 as DOI 10.1099/ ijs.0.63485-0.

Abbreviations: ITS, internal transcribed spacer; PRA, PCR restriction analysis.

The GenBank/EMBL/DDBJ accession number of $16 \mathrm{~S}$ rRNA gene and ITS region sequence of strain $\mathrm{Fl}-93171^{\top}$ is AJ616230.

Antimicrobial susceptibility data for three strains of $M$. florentinum are available as supplementary material in IJSEM Online. typical of rapid growers despite the fact that its members unquestionably belong to slowly growing species, requiring at least 2 weeks of incubation (Tortoli, 2003). The only species known initially to present such unique features was M. simiae; however, since 1993, this species has been joined by many others to embrace 14 taxa at present (Böttger et al., 1993; Fanti et al., 2004; Floyd et al., 1996, 2000; Haas et al., 1997; Levi et al., 2003; Meier et al., 1993; Selvarangan et al., 2004; Springer et al., 1993, 1996; Torkko et al., 2002; Turenne et al., 2004a, b).

Eight mycobacterial strains isolated from clinical human samples drew our attention as they presented an identical lipid profile by HPLC, which differed from known HPLC patterns. Genetic characterization showed that they belonged to a novel species characterized by the genetic properties of the $M$. simiae group. We propose the name Mycobacterium florentinum sp. nov. for this species. 


\section{METHODS}

Strains. Eight independent strains were isolated in the last 11 years from eight patients (Table 1) hospitalized in Italy (seven cases) or in Finland (one case). Six strains were isolated, two or more times, from the sputum of elderly patients. The others were grown from the stools of an AIDS patient and from the excised cervical lymph node of a young girl. Media used for the primary growth varied according to the procedures adopted by different isolating laboratories. Four of the strains were grown on Löwenstein-Jensen medium and in broth (radiometric Bactec, MGIT or BacT Alert), three in liquid medium only and one on Löwenstein-Jensen medium only.

Cultural and biochemical tests. A large selection of biochemical and cultural tests was performed by using established methods and media (Vincent et al., 2003). Biochemical tests included niacin accumulation, nitrate reduction, Tween 80 hydrolysis, urea hydrolysis, tellurite reduction, $\beta$-glucosidase, 3 day arylsulfatase, and semi-quantitative and thermostable catalase. Cultural tests were performed on Löwenstein-Jensen medium to investigate the growth rate, the ability to grow at different temperatures $\left(25,37\right.$ and $\left.45^{\circ} \mathrm{C}\right)$ and the possible production of pigmentation. The ability to grow on MacConkey's agar and the inhibitory effect of several substances $\left[5 \%(\mathrm{w} / \mathrm{v}) \mathrm{NaCl}, 1 \mu \mathrm{g}\right.$ isoniazid $\mathrm{ml}^{-1}, 500 \mu \mathrm{g}$ hydroxylamine $\mathrm{ml}^{-1}$, $250 \mu \mathrm{g}$ oleic acid $\mathrm{ml}^{-1}, 500 \mu \mathrm{g}$-nitrobenzoic acid $\mathrm{ml}^{-1}, 10 \mu \mathrm{g}$ thiacetazone $\mathrm{ml}^{-1}$ ] were also tested.

Chromatographic investigation of the cell-wall lipids. The lipid composition was investigated with different chromatographic approaches. TLC was run on silica gel after methyl esterification (Minnikin et al., 1984) and spots corresponding to mycolic acids were identified by comparison with those of authentic reference strains run in parallel.

Mycolic acid cleavage products, saturated and unsaturated fatty acids and secondary alcohols were investigated with GLC. The fatty acids were extracted as methyl esters by means of methanolysis and injected in a temperature-controlled column where the pyrolysis of mycolic acid occurred (Torkko et al., 2003). GLC and TLC were performed on four strains only (FI-93171 ${ }^{\mathrm{T}}$, FI-93188, FI-94029 and 1696).

All the test strains were also subjected to HPLC. Cell-wall mycolic acids, once saponified and chloroform-extracted, were derivatized to UV-adsorbing mycolic esters and then separated with a gradient of methanol and methylene chloride (Butler et al., 1996).

Antimicrobial susceptibility testing. Antimicrobial susceptibility was investigated in three strains (FI-93171 ${ }^{\mathrm{T}}$, FI-93199, FI-94029) using the macrodilution radiometric method developed for $\mathrm{Myco-}$ bacterium avium complex (MAC). This was made possible as the growth rate of the test strains, very similar to that of MAC, meant that all the requirements of the technique were fulfilled (Siddiqi et al., 1993). Antimicrobial agents are listed in a supplementary table available in IJSEM Online.

Genetic sequencing and phylogenetic investigations. Complete sequences of the 16S rRNA gene and the internal transcribed spacer (ITS) were determined using primers and PCR protocols described previously (Kirschner et al., 1993; Roth et al., 1998). The PCR products were sequenced with an automated apparatus (ALFexpress DNA sequencer; Pharmacia Biotech) using the Thermo Sequenase fluorescent labelled primer cycle-sequencing kit with 7-deaza-dGTP and the Thermo Sequenase Cy5 dye terminator kit (Amersham Pharmacia Biotech). Both the forward and the reverse strands of each strain were sequenced.

The nucleotide sequences were compared with those present in the GenBank and RIDOM (Harmsen et al., 1999) databases. Furthermore,

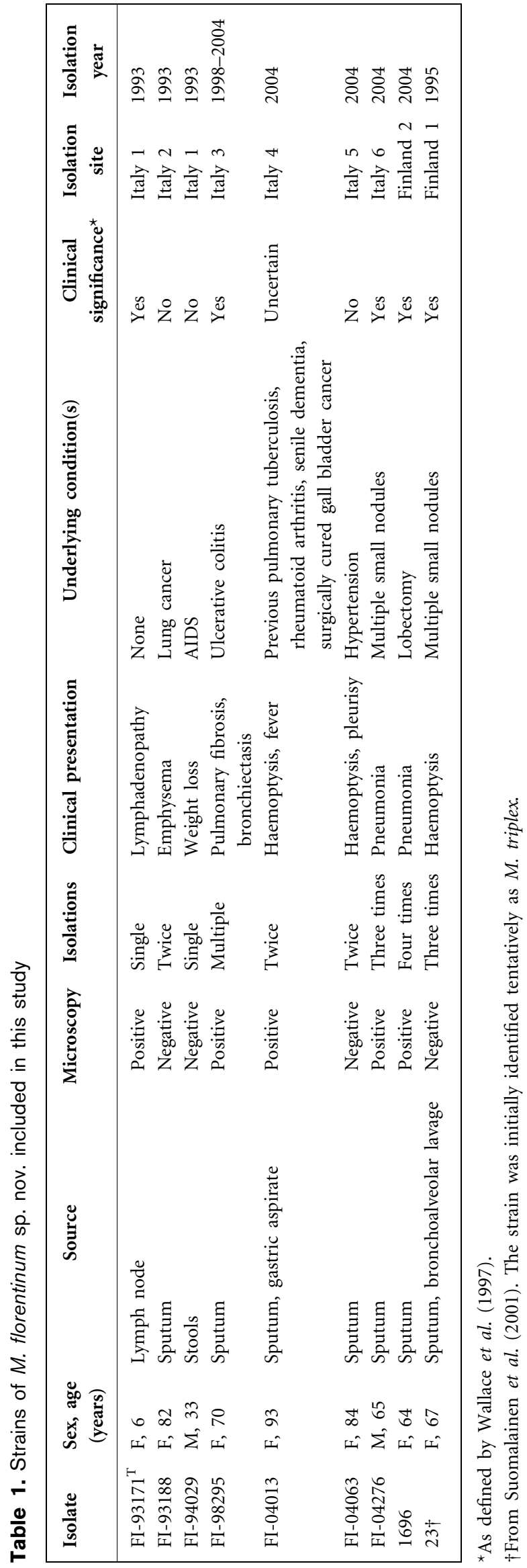


they were aligned with sequences from all other species that were characterized by genetic relatedness to $M$. simiae by using the CLUSTAL w program (European Bioinformatics Institute; http://www.ebi.ac.uk/ clustalw/).

The neighbour-joining method was used for the construction of a phylogenetic tree (Felsenstein, 1993). The tree was rooted using Mycobacterium tuberculosis as the outgroup. Tree branches were reproduced by performing 100 bootstrap replicates.

PCR restriction analysis (PRA). PRA of the $65 \mathrm{kDa}$ heat-shock protein gene ( $h s p 65)$ was performed as previously reported using the enzymes BstEII and HaeIII and separating the digestion products by agarose gel electrophoresis (Telenti et al., 1993). A third enzyme, HhaI, was used to differentiate species with overlapping PRA patterns.

\section{RESULTS AND DISCUSSION}

With minor exceptions, the overlapping of the phenotypic features of the test strains suggested that they could belong to a unique taxon, a hypothesis confirmed by the absolute identity of these strains at the genetic level. The strains undoubtedly belonged to the genus Mycobacterium, as inferred by the acid-alcohol-fastness of the bacilli, the presence of long-chain mycolic acids and, at the genetic level, by the presence of genus-specific regions within the $16 \mathrm{~S}$ rRNA gene. The short helix 18 (a 12-nucleotide deletion near the end of the first third of the 16S rRNA gene) clearly assigned our strains to the group of $M$. simiae-related mycobacteria. The latter feature clearly distinguished them from other slow growers. The species presenting the best match with the test strains were $M$. lentiflavum and M. triplex.

\section{Phenotypic features}

The strains grew in about 2 weeks at 25 and $37^{\circ} \mathrm{C}$, but not at $45^{\circ} \mathrm{C}$ and formed smooth, creamy, non-chromogenic colonies. They reduced tellurite and hydrolysed urea, were unable to accumulate niacin or to hydrolyse Tween 80 and did not possess $\beta$-glucosidase or arylsulfatase. Nitrate reduction was positive in five of the strains and negative or weakly positive in the others; catalase too was variable. Mycobacterial growth was inhibited on MacConkey's agar and on Löwenstein-Jensen medium supplemented with $\mathrm{NaCl}$. No inhibition was observed on media containing isoniazid, hydroxylamine, oleic acid, $p$-nitrobenzoic acid or thiacetazone. The above phenotypic tests did not reveal features helpful in differentiating the organisms from M. triplex or (apart from colony morphology) from M. lentiflavum.

TLC revealed the presence of alpha-, methoxy- and ketomycolates, a pattern very common within the genus Mycobacterium, presented also by M. tuberculosis.

GLC analysis revealed patterns close to those reported for M. lentiflavum and M. triplex. However, the patterns of the novel strains differed from those of both of these species in having the peak for 24:0 higher than that for $26: 0$, and
18:0 higher than that for tuberculostearic acid (10-Me$18: 0$, TBSA); they also differed from $M$. triplex in having 20:0 higher than 22:0 (Fig. 1).

The HPLC pattern fell within the three-clustered motif that characterizes most species genetically related to $M$. simiae. It differed from the latter, however, in the earlier emergence of single clusters and in the very limited height of the peaks in the central cluster (Fig. 2).
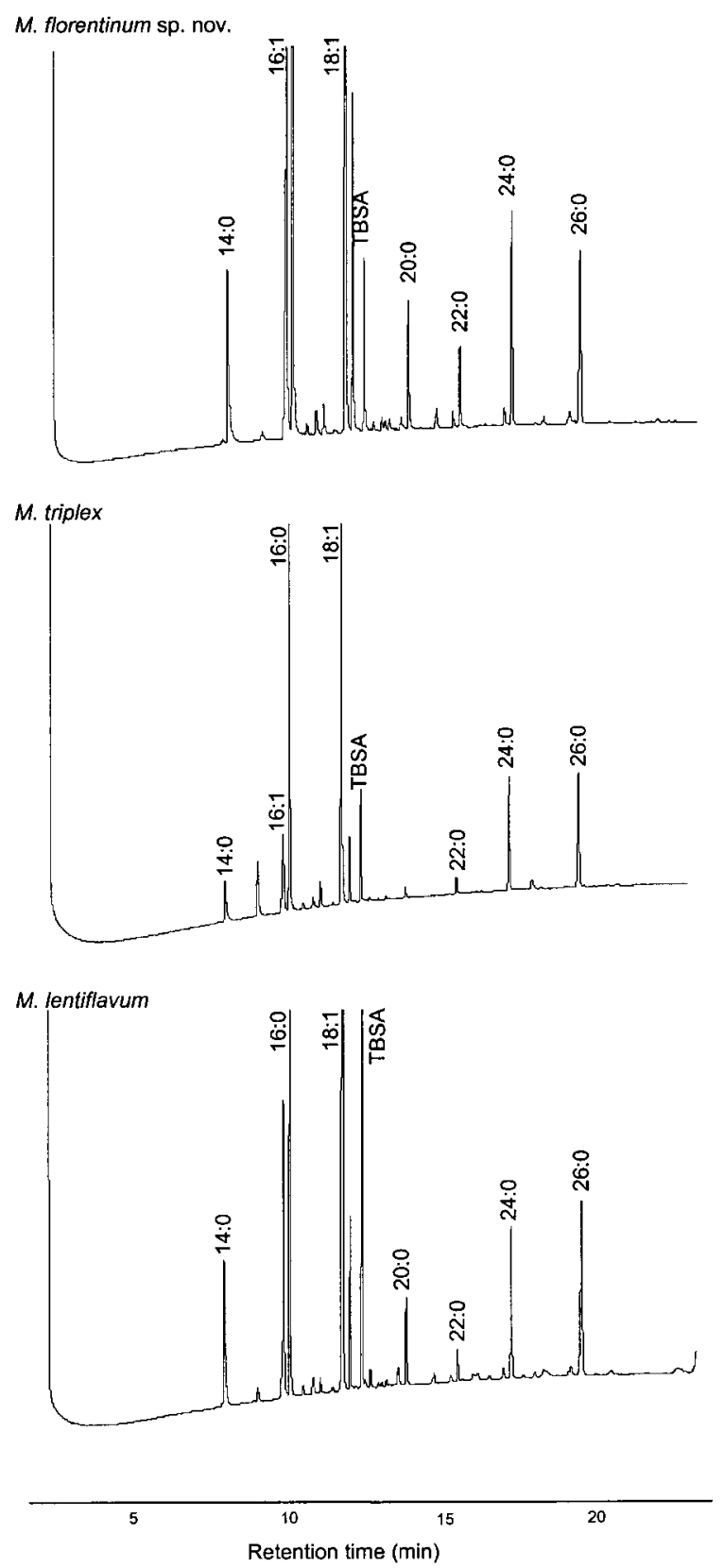

Fig. 1. GLC pattern of the type strain of $M$. florentinum $\mathrm{sp}$. nov. in comparison with those of $M$. triplex and M. lentiflavum. TBSA, Tuberculostearic acid. 


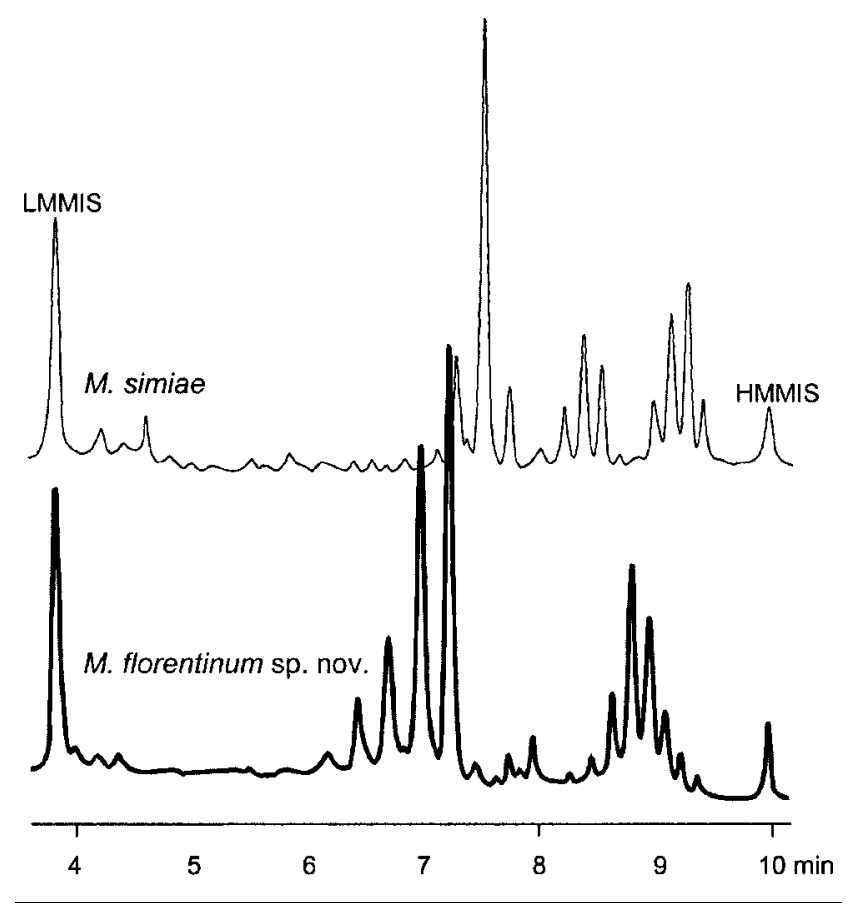

Fig. 2. HPLC profile of the type strain of M. florentinum sp. nov. compared with that of $M$. simiae. LMMIS, Low-molecular-mass internal standard; HMMIS, high-molecular-mass internal standard.

The three strains investigated presented quite high resistance, in particular to quinolones and rifampicin, with only clarithromycin and clofazimine being fully active in vitro (see Supplementary Table A in IJSEM Online).

\section{Genotypic features}

The number of nucleotide mismatches with the most closely related species, M. triplex, was $22(1.2 \%)$ in the $1788 \mathrm{bp}$ stretch including the 16S rRNA gene (8 mismatches) and the ITS (14 mismatches). Such a number of mismatches is clearly higher than that differentiating many of the other recognized species. Within the $16 \mathrm{~S}$ rRNA gene, four mismatches occurred in the first third of the gene, one of them in hypervariable region $\mathrm{A}$, thus allowing differentiation from all other species by studying this region alone.

In the RIDOM database, consisting of the $5^{\prime}$ end of the $16 \mathrm{~S}$ rRNA gene sequences (corresponding to positions 54-510 of the Escherichia coli 16S rRNA gene) of strictly controlled mycobacterial strains, the most closely related species was M. triplex (ATCC $700071^{\mathrm{T}}$ ) which differed by $4 \mathrm{bp}$. In GenBank, the complete sequence of the 16S rRNA gene, and the ITS as well, was $100 \%$ identical to that of a strain tentatively assigned to the species M. triplex, isolate 23 (Suomalainen et al., 2001); however, the sequences of the latter strain and our novel strains differed by $22 \mathrm{bp}$ from the reference strain of that species (ATCC $700071^{\mathrm{T}}$ ).

The position of our strains in the phylogenetic tree was close to M. lentiflavum and the recently described species

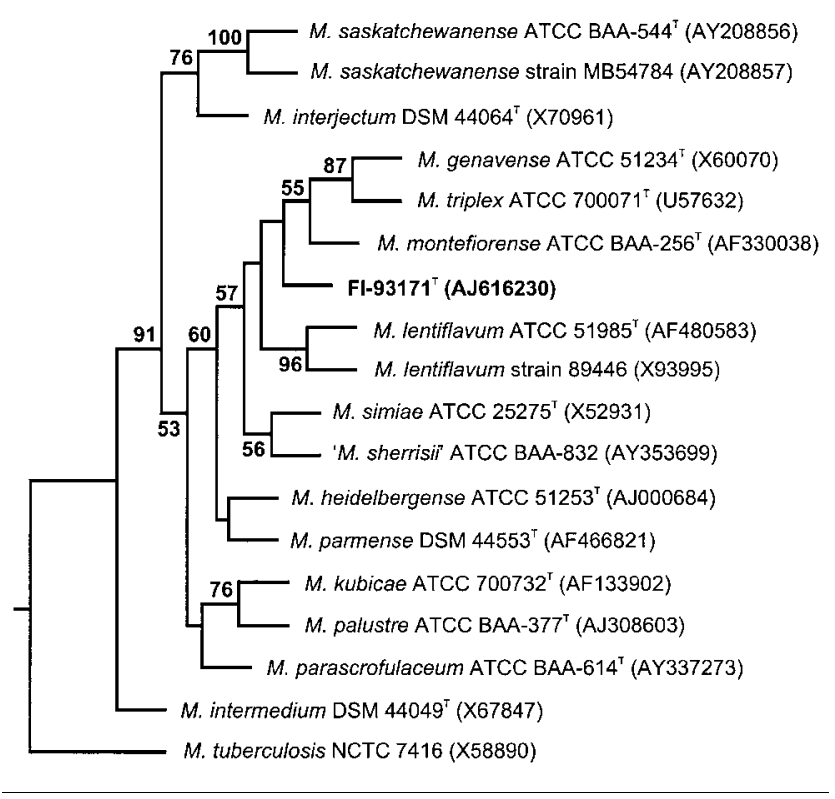

Fig. 3. Neighbour-joining phylogenetic tree based on $16 \mathrm{~S}$ rRNA gene sequences including mycobacterial species genetically related to $M$. simiae. M. tuberculosis NCTC 7416 was used as an outgroup. Numbers on the dendrogram are percentages of occurrence in 100 bootstrapped trees (only values above $50 \%$ are shown).

Mycobacterium montefiorense (Fig. 3). Interestingly, its position was closer to $M$. montefiorense and M. lentiflavum than to M. triplex.

In the PRA, no digestion was produced by BstEII. The use of only the conventionally employed enzymes revealed a pattern that was not distinguishable from M. lentiflavum but clearly different from M. triplex. However, differentiation from $M$. lentiflavum was possible when an additional enzyme, HhaI, was introduced (Table 2).

Three organisms related to $M$. triplex have been reported in the literature. Two of them are different from ours. The first, which was responsible for cervical lymphadenitis, differs in the ITS sequence and the HPLC profile (Hazra et al., 2001). The second, responsible for disseminated infection in an

Table 2. PRA of $h s p 65$ fragments with different restriction enzymes from $M$. florentinum sp. nov. and the most closely related species

Sizes below $50 \mathrm{bp}$ are given in parentheses as their recognition on the gel may be problematic.

\begin{tabular}{|lclc|}
\hline Species & BstEII & \multicolumn{1}{c}{ HaeIII } & HhaI \\
\hline M. florentinum sp. nov. & 441 & $148 / 130 /(35)$ & $235 / 105 / 65$ \\
M. lentiflavum & 441 & $148 / 130 /(35)$ & $235 / 85 / 65$ \\
M. triplex & $325 / 116$ & $148 / 130 / 50 /(35)$ & $235 / 85 / 65$ \\
\hline
\end{tabular}


AIDS patient in France (Zeller et al., 2003), presents four mismatches in a 229-nucleotide 16S rRNA gene fragment. However, the third, isolated in Finland and responsible for a pulmonary infection (Table 1), is identical to our strains, as strongly supported by the sequence identity of both the $16 \mathrm{~S}$ rRNA gene and the ITS (Suomalainen et al., 2001). This latter strain was retrieved and was tested for chromatographic patterns of cell-wall lipids by running in parallel with the test strains. Interestingly, it was found to be identical to the novel strains investigated here.

\section{Description of Mycobacterium florentinum sp. nov.}

Mycobacterium florentinum (flo'ren.ti.num. N.L. neut. adj. florentinum of the Italian city of Florence, where the majority of the strains were collected and investigated).

Non-motile, acid-fast bacillus devoid of spores or capsule. Grows in about 2 weeks at temperatures ranging from 25 to $37^{\circ} \mathrm{C}$, forming unpigmented colonies. The biochemical profile, characterized by positive urease and negative Tween 80 hydrolysis and 3 day arylsulfatase, is not suitable for unambiguous differentiation of strains from several other non-chromogenic species, in particular from $M$. triplex and M. lentiflavum. Among lipid investigations, GLC can differentiate $M$. florentinum sp. nov. from all other related species and the HPLC pattern is unique, although it roughly follows the three-clustered motif characteristic of many M. simiae-related species. M. lentiflavum is the only species that presents a PRA pattern that overlaps with that of M. florentinum sp. nov.; distinction is possible by digesting the DNA with HhaI, however. Finally, the sequences of both the 16S rRNA gene and of the ITS are unique. These data, in addition to its position in the phylogenetic tree, strongly support the novel species status of $M$. florentinum sp. nov.

The type strain, strain FI-93171 ${ }^{\mathrm{T}}\left(=\mathrm{DSM} 44852^{\mathrm{T}}=\mathrm{CIP}\right.$ $108409^{\mathrm{T}}$ ), was isolated from an excised lymph node of a young girl in Italy.

\section{ACKNOWLEDGEMENTS}

The work of L. R. was supported by grants from the Italian 'Istituto Superiore di Sanità' (National Research Program on AIDS) and from MIUR (PRIN 2002-04). We thank Dr S. Armitano, Dr G. L. Molinari and Dr S. Pierdomenico for providing microbiological and clinical information.

\section{REFERENCES}

Böttger, E. C., Hirschel, B. \& Coyle, M. B. (1993). Mycobacterium genavense sp. nov. Int J Syst Bacteriol 43, 841-843.

Butler, W. R., Floyd, M. M., Silcox, M. S. \& 9 other authors (1996). Standardized Method for HPLC Identification of Mycobacteria. Atlanta, GA: CDC, US Department of Health and Human Services.
Fanti, F., Tortoli, E., Hall, L., Roberts, G. D., Kroppenstedt, R. M., Dodi, I., Conti, S., Polonelli, L. \& Chezzi, C. (2004). Mycobacterium parmense sp. nov. Int J Syst Evol Microbiol 54, 1123-1127.

Felsenstein, J. (1993). PHYLIP (phylogeny inference package), version 3.5c. Distributed by the author. Department of Genetics, University of Washington, Seattle, USA.

Floyd, M. M., Guthertz, L. S., Silcox, V. A., Duffey, P. S., Jang, Y., Desmond, E. P., Crawford, J. T. \& Butler, W. R. (1996). Characterization of an SAV organism and proposal of Mycobacterium triplex sp. nov. J Clin Microbiol 34, 2963-2967.

Floyd, M. M., Gross, W. M., Bonato, D. A., Silcox, V. A., Smithwick, R. W., Metchock, B., Crawford, J. T. \& Butler, W. R. (2000). Mycobacterium kubicae sp. nov., a slowly growing, scotochromogenic mycobacterium. Int J Syst Evol Microbiol 50, 1811-1816.

Haas, W. H., Butler, W. R., Kirschner, P. \& 9 other authors (1997). A new agent of mycobacterial lymphadenitis in children: Mycobacterium heidelbergense sp. nov. J Clin Microbiol 35, 3203-3209.

Harmsen, D., Rothganger, J., Singer, C., Albert, J. \& Frosch, M. (1999). Intuitive hypertext-based molecular identification of microorganisms. Lancet 353, 291.

Hazra, R., Floyd, M. M., Sloutsky, A. \& Husson, R. N. (2001). Novel mycobacterium related to Mycobacterium triplex as a cause of cervical lymphadenitis. J Clin Microbiol 39, 1227-1230.

Kirschner, P., Springer, B., Vogel, U., Meier, A., Wrede, A., Kiekenbeck, M., Bange, F. C. \& Böttger, E. C. (1993). Genotypic identification of mycobacteria by nucleic acid sequence determination: report of a 2 -year experience in a clinical laboratory. J Clin Microbiol 31, 2882-2889.

Levi, M. H., Bartell, J., Gandolfo, L., Smole, S. C., Costa, S. F., Weiss, L. M., Johnson, L. K., Osterhout, G. \& Herbst, L. H. (2003). Characterization of Mycobacterium montefiorense sp. nov., a novel pathogenic mycobacterium from moray eels that is related to Mycobacterium triplex. J Clin Microbiol 41, 2147-2152.

Meier, A., Kirschner, P., Schröder, K. H., Wolters, J., Kroppenstedt, R. M. \& Böttger, E. C. (1993). Mycobacterium intermedium sp. nov. Int J Syst Bacteriol 43, 204-209.

Minnikin, D. E., Parlett, J. H., Magnusson, M., Ridell, M. \& Lind, A. (1984). Mycolic acid patterns of representatives of Mycobacterium bovis BCG. J Gen Microbiol 130, 2733-2736.

Roth, A., Fischer, M., Hamid, M. E., Michalke, S., Ludwig, W. \& Mauch, H. (1998). Differentiation of phylogenetically related slowly growing mycobacteria based on 16S-23S rRNA gene internal transcribed spacer sequences. J Clin Microbiol 36, 139-147.

Selvarangan, R., Wu, W. K., Nguyen, T. T. \& 10 other authors (2004). Characterization of a novel group of mycobacteria and proposal of Mycobacterium sherrisii sp. nov. J Clin Microbiol 42, 52-59.

Siddiqi, S. H., Heifets, L. B., Cynamon, M. H., Hooper, N. M., Laszlo, A., Libonati, J. P., Lindholm-Levy, P. J. \& Pearson, N. (1993). Rapid broth macrodilution method for determination of MICs for Mycobacterium avium isolates. J Clin Microbiol 31, 2332-2338.

Springer, B., Kirschner, P., Rost-Meyer, G., Schröder, K. H., Kroppenstedt, R. M. \& Böttger, E. C. (1993). Mycobacterium interjectum, a new species isolated from a patient with chronic lymphadenitis. J Clin Microbiol 31, 3083-3089.

Springer, B., Wu, W. K., Bodmer, T. \& 10 other authors (1996). Isolation and characterization of a unique group of slowly growing mycobacteria: description of Mycobacterium lentiflavum sp. nov. J Clin Microbiol 34, 1100-1107.

Suomalainen, S., Koukila-Kähkölä, P., Brander, E., Katila, M. L., Piilonen, A., Paulin, L. \& Mattson, K. (2001). Pulmonary infection caused by an unusual, slowly growing nontuberculous mycobacterium. J Clin Microbiol 39, 2668-2671. 
Telenti, A., Marchesi, F., Balz, M., Bally, F., Böttger, E. C. \& Bodmer, T. (1993). Rapid identification of mycobacteria to the species level by polymerase chain reaction and restriction enzyme analysis. J Clin Microbiol 31, 175-178.

Torkko, P., Suomalainen, S., livanainen, E., Tortoli, E., Suutari, M., Seppänen, J., Paulin, L. \& Katila, M. L. (2002). Mycobacterium palustre sp. nov., a potentially pathogenic, slowly growing mycobacterium isolated from clinical and veterinary specimens and from Finnish stream waters. Int J Syst Evol Microbiol 52, $1519-1525$.

Torkko, P., Katila, M. L. \& Kontro, M. (2003). Gas-chromatographic lipid profiles in identification of currently known slowly growing environmental mycobacteria. J Med Microbiol 52, 315-323.

Tortoli, E. (2003). Impact of genotypic studies on mycobacterial taxonomy: the new mycobacteria of the 1990s. Clin Microbiol Rev 16, 319-354.

Turenne, C. Y., Thibert, L., Williams, K., Burdz, T. V., Cook, V. J., Wolfe, J. N., Cockcroft, D. W. \& Kabani, A. (2004a). Mycobacterium saskatchewanense sp. nov., a novel slowly growing scotochromogenic species from human clinical isolates related to Mycobacterium interjectum and Accuprobe-positive for Mycobacterium avium complex. Int J Syst Evol Microbiol 54, 659-667.

Turenne, C. Y., Cook, V. J., Burdz, T. V., Pauls, R. J., Thibert, L., Wolfe, J. N. \& Kabani, A. (2004b). Mycobacterium parascrofulaceum sp. nov., novel slowly growing, scotochromogenic clinical isolates related to Mycobacterium simiae. Int J Syst Evol Microbiol 54, 1543-1551.

Vincent, V., Brown-Elliott, B. A., Jost, K. C., Jr \& Wallace, R. J., Jr (2003). Mycobacterium: phenotypic and genotypic identification. In Manual of Clinical Microbiology, pp. 560-584. Edited by P. R. Murray, E. J. Baron, J. H. Jorgensen, M. A. Pfaller \& R. H. Yolken. Washington, DC: American Society for Microbiology.

Wallace, R. J., Jr, Glassroth, J., Griffith, D. E., Oliver, K. N., Cook, J. L. \& Gordin, F. (1997). Diagnosis and treatment of disease caused by nontuberculous mycobacteria. Official Statement of the American Thoracic Society Am J Respir Crit Care Med 156, S1-S25.

Zeller, V., Nardi, A. L., Truffot-Pernot, C., Sougakoff, W., Stankoff, B., Katlama, C. \& Bricaire, F. (2003). Disseminated infection with a mycobacterium related to Mycobacterium triplex with central nervous system involvement associated with AIDS. J Clin Microbiol 41, 2785-2787. 